DOT/FAA/AM-97/10

Office of Aviation Medicine Washington, D.C. 20591

\section{Evaluation of a Range of Target Blink Amplitudes for Attention- Getting Value in a Simulated Air Traffic Control Display}

Nelda J. Milburn

Henry W. Mertens

Civil Aeromedical Institute

Federal Aviation Administration

Oklahoma City, Oklahoma 73125

April 1997

Final Report

This document is available to the public through the National Technical Information Service, Springfield, Virginia 22161.

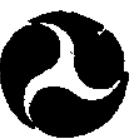

U.S. Department of Transportation

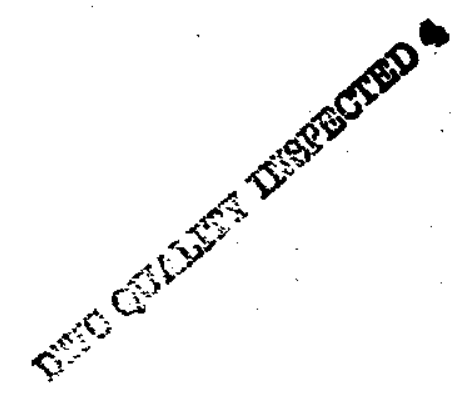




\section{NOTICE}

This document is disseminated under the sponsorship of the U.S. Department of Transportation in the interest of information exchange. The United States Government assumes no liability for the contents or use thereof. 


\section{Evaluation of a Range of Target Blink Amplitudes for Attention- Getting Value in a Simulated Air Traffic Control Display}

\section{INTRODUCTION}

Several sources (Anastasi, Hill, Murphy, Cardosi, Guttman, \& Amaldi, 1995; Boff \& Lincoln, 1988; Christ, 1975; Gerathewohl, 1951; 1952; 1953; 1954; Gilmore, Gertman, and Blackman, 1989; Military Standards, 1989; Van Orden and DiVita, 1993) suggest that blinking targets are more alerting than steady targets, and can aid the user in finding the targets quickly. Those sources recommend target size, color, shape, brightness contrast, frequency of blink and parameters for the satio of time the blink should be "on" relative to the time it is "off." However, no guidelines in the literature were found for an effective, attention-getting blink amplitude. Since all studies involved blinking in which on and off states $100 \%$ change in intensity) were alternated, 2 recommendation of $100 \%$ amplitude change during blinking seems implied.

A previous study (Mertens \& Milbura, 1996) evaluated the effectiveness of redundant color coding for protecting the performance of individuals with color vision deficiency in a simulated air traffic control search task requiring search for, and identification of, the data blocks for specific aircraft. The display characteristics of that study simulated the information coding design used in the situation display of a developmental system called the Initial Sector Suite System (ISSS), a system now discontinued, that was originally intended to provide the next generation of work stations for radar controllers. Blinking in that study emulated prototype displays that were observed and involved amplitude modulation of approximately $20 \%$ rather than $100 \%$, as typically used in the literature on blinking (flashing, flicker) for highlighting. The frequency was $2 \mathrm{HZ}$ and the duration of the blink intensity decrement was approximately $1 / 10 \mathrm{sec}$. The small $(20 \%)$ change in intensity during blink had little artention-getting value, as confirmed by experimental findings of Mertens and Milburn (1996).

Blinking in the ISSS displays was ostensibly designed to reduce the attention-getting and distraction effects of blinking and possibly to reduce the effect of blinking on legibility by maintaining visible presence throughout the blink cycle. There is some debate in the literature concerning the distracting qualities of blinking on a display screen (Van Orden, DiVita \& Shim, 1993; Van Orden \& DiVita, 1993). While that is an area in need of research, the present study focuses on the attention-getting or alerting value of blinking. If blinking caused distraction in certain circumstances, it would be due to its powerful attentiongetting characteristic. It remains a cue that is potentially useful for attracting attention in critical situations and may also be useful as a redundant cue in those situations where color coding is used for attention-getting.

The purpose of this pilot study was to evaluate the effectiveness of a range of blink amplitudes for aiding the visual search for, and identification of, aircraft in a simulared air traffic control situation display. This experiment is limited to the case of blink involving a repeated brief decrease from normal intensity. The amplitude of blink is defined as the percentage of decrease in luminance from the normal luminance of targets. The case of increase in intensity relative to the normal is not dealt with here. 


\section{METHOD}

\section{Participants}

Prior approval for all procedures and use of human participants was obtained from the Office of Aviation Medicine/Civil Aeromedical Institute human use committee. Volunteers were recruited froin the Human Resources Research Division of the Civil Aeromedical Institute. The informed consent of every participant was obtained prior to participation, and each participant was free to withdraw from the experiment without prejudice at any time during the experiment.

Ten co-workers, 7 females and 3 males, served as participants for this pilot study. Participants had a mean age of 35.1 years and a standard deviation of 6.2 years. All volunteers had normal color vision and at least 20/30 visual acuity in both near and distant vision as determined with the Bausch and Lomb Orthorater. Normal color vision was determined by a battery of clinical color vision tests that included the Dvorine, the Ishihara 24-plate, the American Optical - Hardy, Rand, Rittler (AOC-HRR) Pseudo-Isochromatic Plate Tests, and the Farnsworth F2 Plate Test.

\section{Performance Measures:}

Performance was measured in terms of accuracy and search time. Errors included misses (the failure to select 2 target), and false alarms (the selection of nontargets). Two additional accuracy measures were calculated, percent correct of all targets (possible 26 per condition), and a pass/fail score based on correct trials (possible 18 per condition). An incorrect trial was defined as any trial on which at least one target was missed or a non-target was selected as a target. The search time measure was defined as the time required to select targets and terminate the trial.

\section{Procedures}

The ATC situation display consisted primarily of aircraft symbols, each with a block of alphanumeric data attached by a leader line to the aircraft symbol. The alphanumeric data, called the data block, contains information about the state of the aircraft, e.g., call sign, aircraft type, heading, altitude, and groundspeed. The aircraft symbols and their data blocks are positioned about the situation display on paths describing the flight of each aircraft. Map data describing boundaries of air traffic control sectors, geographic data, and navigation references.were also included in the situation display. The participant was instructed to locate all of the blinking data block targets, select them using a mouse, and press the "ENTER" key to advance to the next trial. They searched for either $0,1,2$, or 3 targets within a field of 16 aircraft (data blocks) on the simulated ATC situation display. Data blocks other than the blinking targets were called distractors. Each experimental condition consisted of 1 demonstration trial that illustrated the amplitude of the blink for the targets in that condition, followed by 5 practice trials and 18 test trials. Two trials contained 3 targets, 8 trials contained 2 targets, 4 trials contained 1 target, and 4 trials contained 0 targets. Participants were informed that some trials would present screens containing no targets. For those trials, the participant was asked to press the ENTER key as soon as he or she had determined that there was no target on the screen.

A control condition was also presented to obtain 2 baseline and estimation of the optimum response time. The control condition consisted of trials with display screens that were identical to those presented in the experimental conditions, except that they contained no distractor targets. All data blocks on the screen were targets, and the participant's task was to select them as quickly as possible. The targets were displayed on the same background map as used for trials with distractors, and the locations of targets were varied by the same techniques as for trials with distractors.

The 7 amplitudes of blink were, 100\%, 93.75\%, $87.5 \%, 75 \%, 50 \%, 25 \%$, and $12.5 \%$. For this study, target blink amplitude is defined as the percentage of decrease in luminance from a standard of $51.4 \mathrm{Cd} / \mathrm{m}^{2}$ at a rate of $2 \mathrm{HZ}$, and the duration of the blink intensity decrement was approximately $1 / 10 \mathrm{sec}$.

The instructions urged the participants to respond quickly and accurately, with the emphasis on accuracy. All conditions were self-paced and four 5 minute breaks were programmed into each participant's unique random order of conditions, so that the breaks were evenly spaced throughout the experiment. All participants completed the experiment within 2 hours. 


\section{RESULTS}

Table 1 presents means and standard deviations for misses, and means for false-alarms and percent correct for all trials under each of the amplitude conditions. On the average, participants made very few false alarms for any of the different blink amplitude levels. Most errors were misses, defined as 2 failure to detect and select a blinking target. When the targets were difficult to detect, some respondents terminated the trial without finding any targets, or without finding all of the targets on the trials that contained multiple targets. High miss rates and low false alarm rates were typical in conditions involving a small change in amplitude ranging from $12.5 \%$ to $25 \%$. Of the types of errors discussed, misses are the most critical type in air traffic control work. A false alarm might result in the air traffic controller making some additional mental calculations, with a loss of time, but failure to quickly find an emergency warning or critical event displayed on the ATC situation display could result in a loss of required separation between aircraft.

Table 1 also contains the mean percent correct for all 26 targets of a particular amplitude condition calculated for the 10 participants. For amplitudes between $50 \%$ to $100 \%$, performance was $96 \%$ correct or better. However, for the $25 \%$ amplitude condition, participants averaged only $71 \%$ correct and their response time was more than twice as long as the average for the $50 \%$ amplitude condition.

In a separate analysis, each trial for each individual was scored as correct or incorrect. For a trial to be scored as correct, the participant must not have selected any non-targets (false alarms) or missed any of the blinking targets for that trial. Using this scoring procedure, a single incorrect trial in the scores of 18 trials resulted in $94.4 \%$ correct, and 2 incorrect trials equaled $\mathbf{8 8 . 8 \%}$ correct. A pass/fail criterion of less

\section{Table 1}

Means and Standard Deviation by Amplitude for Misses, and Means
for False-Alarms, Percent Correct, and Response Times for Correct Trials

\begin{tabular}{|c|c|c|c|c|c|}
\hline & $\begin{array}{l}\text { Mileses } \\
\text { (moans) }\end{array}$ & $\begin{array}{l}\text { Misees } \\
\text { (std dev) }\end{array}$ & $\begin{array}{c}\text { Falso-Alarms } \\
\text { (means) }\end{array}$ & $\begin{array}{l}\text { Percent } \\
\text { Correct } \\
\text { (means) }\end{array}$ & $\begin{array}{c}\text { Response } \\
\text { Times } \\
\text { (means) }\end{array}$ \\
\hline \multicolumn{6}{|c|}{ CONTROL CONDITION } \\
\hline $\begin{array}{l}\text { No Distractors } \\
\text { (Non-Blinking) }\end{array}$ & 0.1 & .32 & 0 & 99.69 & 3.93 \\
\hline \multicolumn{6}{|c|}{ PERCENT OF DECREASE W AMPLTTUDE } \\
\hline 100 & 0.1 & .32 & 0 & 99.69 & 6.91 \\
\hline 93.75 & $\mathbf{0}$ & 0 & 0 & 100 & 7.63 \\
\hline 87.5 & 0 & 0 & 0 & 100 & 7.76 \\
\hline 75 & 0 & 0 & 0 & 100 & 8.29 \\
\hline 50 & 0.8 & 1.32 & 0 & 96.88 & 11.59 \\
\hline 25 & 5.5 & 4.38 & 0.1 & 71.25 & 28.94 \\
\hline 12.5 & 16.4 & 7.40 & 3.0 & 36.46 & 22.46 \\
\hline
\end{tabular}


than 2 errors was arbitrarily established for each condition, and pass/fail percentage rates are shown in Table 2. For the $75 \%$ to $100 \%$ amplitude conditions, a pass rate of $100 \%$ was maintained. A $90 \%$ pass rate was obtained for the $50 \%$ amplitude condition. This may be considered marginal performance, if an average $8 \%$ miss rate is considered unacceptable performance. Of course, this depends on the criticality of the signal. For the $25 \%$ and the $12.5 \%$ amplitude conditions, the pass rates were $20 \%$ and $0 \%$, respectively.

Some blink amplitudes had such poor attentiongetting value that 2 respondents were unable to find even a single target of the 26 possible during an 18trial experimental condition. Figure 1 presents the percent correct for each condition by the number of targets. Figure 1 shows the stable performance for conditions involving a $75 \%$ to $100 \%$ decrease in brightness and the steady increase in errors (missed targets and selection of nontargets) for the $50 \%, 25 \%$, and $12.5 \%$ decreases in brightness. Performance in conditions involving amplitudes of $75 \%$ to $100 \%$ is clearly stable and acceptable, ranging from $98.75 \%$ to $100 \%$, and performance is unacceptable in terms of errors for amplitudes of $25 \%$ or less, ranging from $5 \%$ correct to $72.5 \%$ correct for 1,2 , and 3 target trials. Performance on the zero target trials was consistently $100 \%$ for amplitudes greater than $50 \%$, but as targets became more difficult to detect, participants began to make more guesses, which are reflected in the occurrence of false alarms in the $25 \%$ and $12.5 \%$ amplitude conditions. The $50 \%$ amplitude condition appears to be at the point at which a statistical test should be used to determine whether errors significantly increased from the $75 \%$ amplitude condition. Results from a paired-sample t-test indicated that the increase in errors was not significant, $t(\mathrm{df}=9, \alpha=.05)=1.92, p=$ .087 . Because the mean errors in the $75 \%$ amplitude condition is zero, these results are identical to a onesample t-test that compares the mean for the $50 \%$ amplitude condition (0.8) to zero.

Response time performance by amplitude, as a function of the number of targets, is presented as bar graphs in Figure 2. Response time remained steady for the larger blink amplitudes $(75 \%$ to $100 \%$ decrease in brightness), but response time substantially increased as the percentage of change in brightness was reduced ( $50 \%, 25 \%$, and $12.5 \%$ conditions). A paired-sample t-test was used to determine whether the response times differed significantly between the $75 \%$ amplitude condition and the $50 \%$ amplitude condition. Results indicate that there is no significant difference between those 2 conditions, $t(d f=9, \alpha=.05)=2.06$, $p=.069$. The response times shown are for correct trials only. The apparent drop in response time for the 3 target, $12.50 \%$ decrease in brightness condition was based on a single participant's response time for a single triai. Only 1 participant correctly identified the 3 targets, but only in 1 trial. All the other participants missed 1,2, or 3 targets for both of the 3-target trials at that amplitude.

\section{Table 2}

\section{Percent Passing With Less Than Two Errors For 18 Trials}

\begin{tabular}{|c|c|}
\hline \multicolumn{2}{|c|}{ PASS } \\
\hline CONTROL CONDITION \\
\hline NO Distractors & $100 \%$ \\
\hline PERCENT OF DECREASE IN AMPLUTUDE \\
\hline 100 & $100 \%$ \\
\hline 93.75 & $100 \%$ \\
\hline 87.5 & $100 \%$ \\
\hline 75 & $100 \%$ \\
\hline 50 & $90 \%$ \\
\hline 25 & $20 \%$ \\
\hline 12.5 & $0 \%$ \\
\hline
\end{tabular}


Figure 1

Percent Correct by Amplitude and by Number of Targets

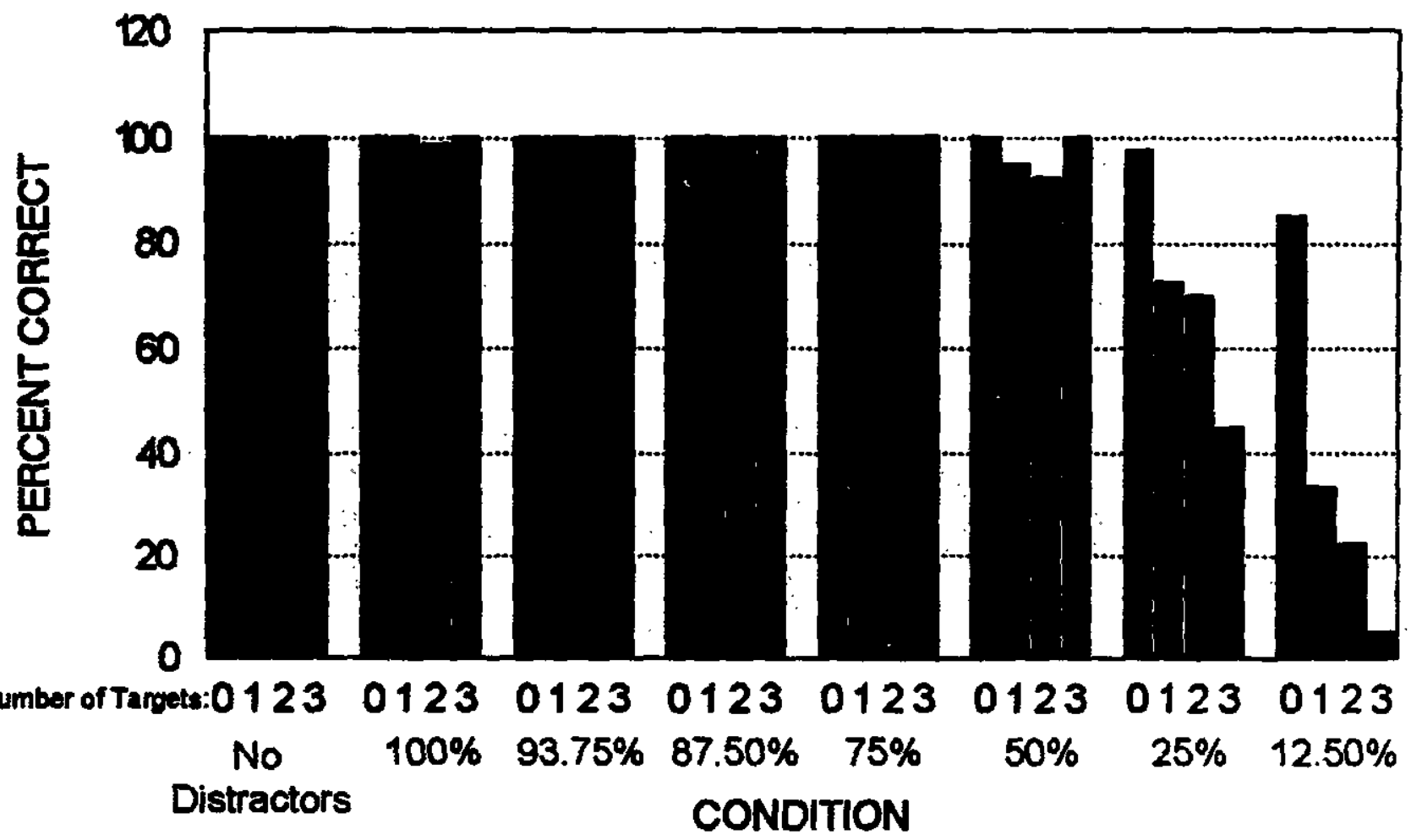

Figure 2

Response Time by Amplitude and by Number of Targets

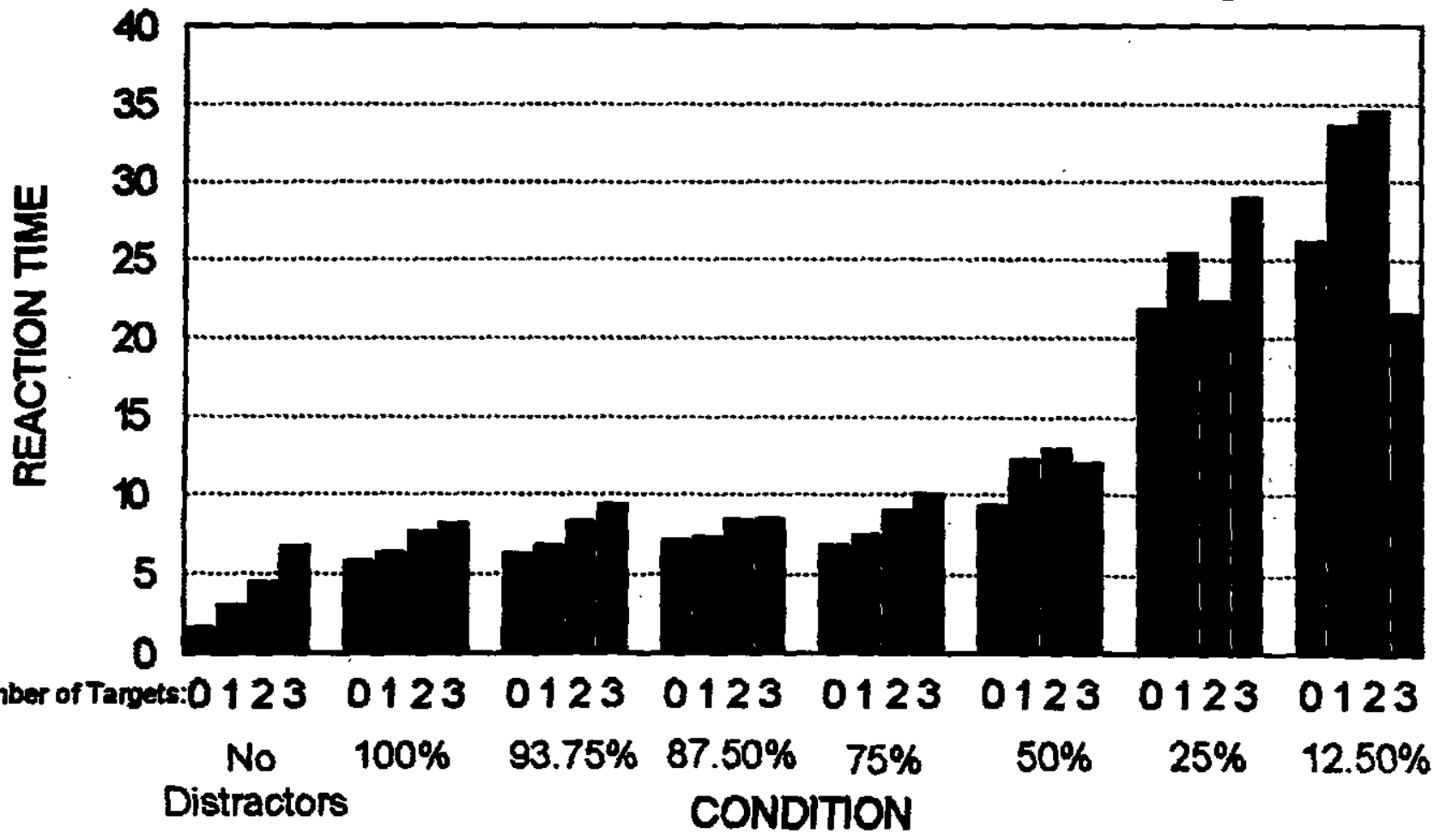




\section{DISCUSSION}

The objective of this research was to determine the level of blink amplitude that can capture the user's attention quickly and with a high degree of regularity (at least $95 \%$ of the time). Figure 3 illustrates the relationship between accuracy and response time undet each of the blink amplitude and control conditions. Stable accuracy and response time performance is maintained for amplitudes ranging from $75 \%$ to $100 \%$, and a steep decline in accuracy, combined with increasing response times, is evident for the amplitudes ranging from $12.5 \%$ to $25 \%$. This figure should aid display designers in their selection of an optimum blink amplitude for atrentional purposes based on both of those performince measures. Other considerations for selection of an optimum blink might include other parameters of blinking, for example, frequency, on/off time retio, and so forth, and the consequent effects of blink on distractibility and legibility. $A$ blinking target may be distracting if it diverts ones attention away from the desired focus.
Distractibility was not examined in this experiment, but it may be an important factor in creating 2 userfriendly display.

Anastasi, Hill, Murphy, Cardosi, Guttman, and Amaldi (1995) state that, "All coding techniques have advantages and disadvantages. For example, flash coding is good for attracting attention, but flashing text is difficult to read." Just as it may be necessary to accept some degree of distraction to ensure that a warning alert is noticed, compromises concerning legibility may also be necessary. The legibility of text under blinking conditions is an issue for further research. With blink amplitudes less than $100 \%$, the legibility of text might be preserved to some degree. Gilmore, Gertman, and Blackman (1989) suggest that the legibility of the text can be preserved by placing a separate blinking symbol near the critical information. Whichever method is used, if blink is employed for attention-getting purposes, based on this pilot study, blink amplitudes less than $75 \%$ are not recommended for safety-critical applications.

\section{Figure 3}

\section{Means for Percent Correct and Response Times for the Control and Experimental Conditions}

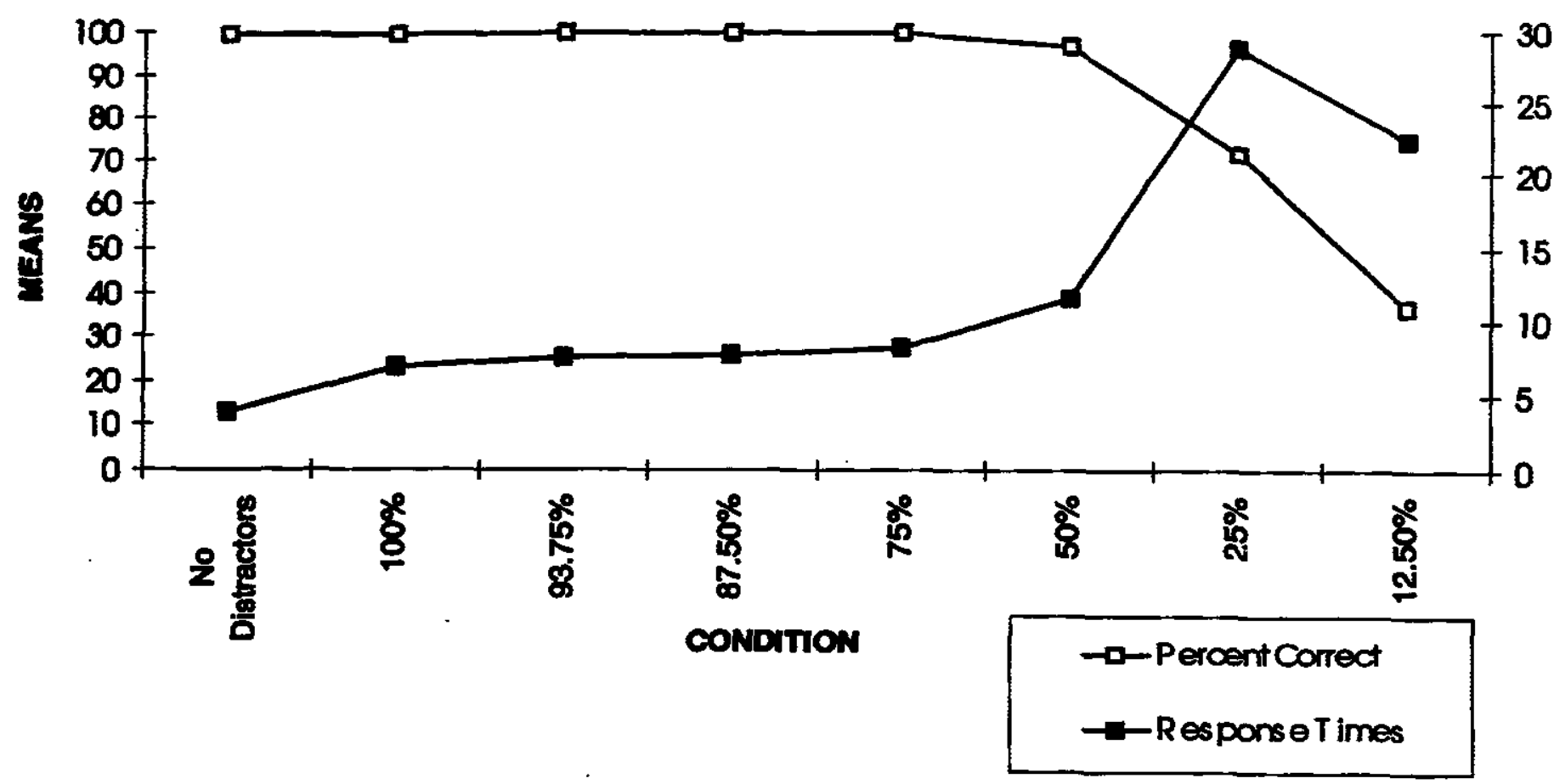




\section{REFERENCES}

Anastasi, D.L., Hill, B.P., Murphy, E.D., Cardosi, K.M., Guttman, J.A., \& Amaldi, P. (1995). ComputerHuman Interface (CHI) Considerations in Human Factors in the Design and Evaluation of Air Traffic Control Systems. DOT/FAARD-95/3. Office of Aviation Research, Washington, DC 20591.

Boff, K.R., \& Lincoln, J.E. (Eds.). (1988). Engineering Data Compendium: Human Perception and Performance. AAMRL, Wright-Patterson AFB, OH.

Christ, R.E. (1975). Review and analysis of color coding research for visuai displays. Human Factors. 17(6) 542-570.

Gerathewohl, S.J. (1951). Conspicuity of flashing and steady light signals. I. Variation of contrest. USAF School of Aviation Medicine, Special Report.

Gerathewohl, S.J. (1952). Conspicuity of flashing and steady light signals. II. High contrasts. USAF School of Aviation Medicine, Special Report.

Gerathewohl, S.J. (1953). Conspicuity of flashing and steady light signals: Variation of contrasts. Joumal of Optical Society of America. 43, 567-571.
Gerathewohl, S.J. (1954). Conspicuity of flashing light signals of different frequency and duration. Journal of Experimental Psychology. 48 (4) 247-251.

Gilmore, W.E., Gertman, D.I., and Balckman, H.S. (1989). The user-computer interface in process control: $A$ human factors engineering handbook. New York: Academic Press.

Mertens, H.W., \& Milburn, N.J. (1996, in preparation). Effects of color vision deficiency on detection of highlighted targets in a simulated air traffic control display.

Military Standarais, MIL-STD-1472D, (1989). Human Engineering Design Criteria for Military Systems, Equipment and Facilities.

Van Orden, K.F., \& Di Vita, J. (1993). Highlighting with flicker: some basic visual search considerations. Proceedings of the Human Factors and Ergonomics Society 37th Annual Meeting - 1993. 13001304.

Van Orden, K.F., Di Vita, J, \& Shim, M.J. (1993). Redundant use of luminance and flashing with shape and color as highlighting codes in symbolic displays. Human Factors. 35(2) 195-204. 